\title{
José Ortega y Gasset y la generación de 1911. Reflexiones en torno a la filosofía "post-neokantiana»
}

\section{José Ortega y Gasset and the Generation of 1911. Reflections on «Post-Neokantian» Philosophy}

\author{
DOROTA LESZCYNA \\ Universidad de Breslavia (Wrocław), Polonia
}

Recibido: 29-I-2014 Aprobado: 20-II-2014

\begin{abstract}
RESUMEN
El intento del presente artículo es investigar el lugar de Ortega en el panorama del pensamiento europeo, especialmente alemán, de la primera mitad del siglo XX, utilizando uno de los conceptos fundamentales de su filosofía, es decir, el concepto de la «generación». Por tanto se defiende la tesis de que Ortega puede ser considerado como uno de los representantes de la generación post-neokantiana llamada por él mismo la generación de 1911 y que el pensamiento orteguiano se inscriba en el programa intelectual de filósofos como: Nicolai Hartmann, Heinz Heimsoeth, Karl Jaspers o Martin Heidegger. Todos estos filósofos brotan de la tradición neokantiana y la superan creando una nueva actitud filosófica centrándose en la reflexión ontológica y en el proyecto de superar el idealismo moderno.
\end{abstract}

PALABRAS CLAVES

ORTEGA, GENERACIÓN, NEOKANTISMO, POST-NEOKANTISMO, ONTOLOGÍA, IDEALISMO

\section{ABSTRACT}

The aim of this paper is to investigate the site of Ortega in the panorama of European, especially German thought, in the first half of the twentieth century, using one of the fundamental

(C) Contrastes. Revista Internacional de Filosofía, vol. XX-Nº1 (2015, pp. 7-26. ISSN: 1136-4076

Departamento de Filosofía, Universidad de Málaga, Facultad de Filosofía y Letras Campus de Teatinos, E-29071 Málaga (España) 
concepts of his philosophy, that is, the concept of «generation». Therefore I will defend the thesis that Ortega can be considered as one of the representatives of the post-neo-Kantian generation, called by himself the «generation of 1911» and that Ortega's thought participates in the intellectual program of philosophers such as: Nicolai Hartmann, Heinz Heimsoeth, Karl Jaspers or Martin Heidegger. All these philosophers emerge from the neo-Kantian tradition but it overcomes, creating a new philosophical attitude, focusing on ontological reflection and on the project to overcome modern idealism.

KEYWORDS

ORTEGA, GENERATION, NEO-KANTIANISM, POST-NEO-KANTIANISM, ONTOLOGY, IDEALISM

\section{INTRODUCCIÓN}

José OrTega y Gasset (1883-1955) es uno de los más significativos e importantes filósofos españoles en la historia de este país. Su influencia en la vida intelectual de España del siglo XX es evidente y comunmente aceptada. Ortega sigue siendo objeto de viva investigación y por ello siguen apareciendo, con frecuencia, nuevos estudios que van completando el inacabado conocimiento de su filosofía. Sin embargo, todavía quedan en Ortega muchos aspectos desconocidos o insuficientemente analizados que esbozan un horizonte para una nueva investigación.

Mi interés creciente y trabajos sobre este pensador español me llevó, de forma natural, a querer conocer el aspecto histórico de su obra y los vínculos que le unen con otros representantes de su época filosófica.

Por tanto, en este artículo indago en las zonas menos conocidas que están relacionadas con el lugar de Ortega en el panorama del pensamiento europeo, especialmente alemán, del siglo XX, utilizando uno de los conceptos fundamentales de su filosofía, es decir, el concepto de la generación.

Así, pretendo defender la tesis de que Ortega puede ser considerado, desde el punto de vista de la filosofía europea de la primera mitad del siglo XX, como uno de los representantes de la generación post-neokantiana llamada por él mismo la generación de 1911 y que el pensamiento orteguiano se inscriba en el programa intelectual de filósofos como: Nicolai Hartmann, Heinz Heimsoeth, Karl Jaspers o Martin Heidegger. Todos estos filósofos brotan de la tradición neokantiana y la superan creando una nueva actitud filosófica centrándose en la reflexión ontológica.

\section{El CONCEPTO DE LA GENERACIÓN EN ORTEGA}

El concepto de la generación, que según Ortega, tiene el sentido esencial para los estudios histórico-filosóficos, permite penetrar el fondo cultural de 
cada doctrina filosófica y conocer la energía vital de su autor o, como afirma Ortega, su «sensibilidad vital» 1 .

La sensabilidad vital es, para nuestro pensador, una manifestación del cáracter histórico de la vida de cada cual que, brotando de una determinada circunstancia de una vida colectiva, se entrelaza con la vida de otros individuos y entra con ellos en múltiples relaciones.

Ahora bien, las variaciones de la sensibilidad vital se manifiestan bajo la forma de generación. Por generación cabe entender una variedad humana que forma un cuerpo social íntegro, abarcando tanto las minorías selectas, que a través de su actividad cultural crean la realidad histórica, como la muchedumbre que tiene carácter receptivo y pasivo: Es, como establece Ortega, «un compromiso dinámico entre masa e individuo» ${ }^{2}$.

Así, cada generación consiste en diferentes individuos humanos, «dotados - según Ortega - de ciertos caracteres típicos, que les prestan fisonomía común, diferenciarlos de la generación anterior» ${ }^{3}$. La generación abarca, pues, los hombres que tienen distintas personalidades, ansias, aspiraciones, pero los une la misma estructura de la sensibilidad vital y el mismo modo de sentir su existencia que se refleja en un cierto programa intelectual y destino común que hay que cumplir.

Ahora bien, las reflexiones orteguianas sobre el problema de la generación nos llevan, de forma natural, al siguiente problema: ¿cual es la generación de Ortega? Aunque tal pregunta parece obvia, la respuesta es bastante problemática y complicada.

En los estudios dedicados a la filosofía orteguiana aparecen diferentes perspectivas respecto a este problema. Por ejemplo, algunos expertos, sobre todo polacos, consideran a Ortega como uno de los representantes del movimiento literario y filosófico llamado la generación de $1898^{4}$, en base a su proyecto común de revitalizar la vida de España a través de su europeización; mientras

1 Ortega establece que la sensibilidad vital es «el fenómeno primario en historia» e imprescindible para entender una época histórica. J. Ortega y Gasset, El tema de nuestro tiempo, en Obras completas III. Madrid: Revista de Occidente/Taurus, 2005, p. 562.

2 «La generación, compromiso dinámico entre masa e individuo, es el concepto más importante en la historia, y, por decirlo así, el gozne sobre que ésta ejecuta sus movimientos». Ibid., p. 563.

3 Ibid.

4 En Polonia hasta los últimos años existía una tendencia de interpretar la filosofía orteguiana como un reflejo de las ideas reformadoras de la generación del 98. Tal interpretación aparece, por ejemplo, en S. Cichowicz, O refleksję konkretną. Cztery przyklady historyczne. Gdańsk: Słowo/Obraz/Terytoria, 2002, pp. 54-55. 
que los expertos españoles incorporan a Ortega a otra generación conocida como la generación de $1914^{5}$.

Retomando el concepto de generación de Ortega convertido en método de la investigación histórica, podemos comprobar muy fácilmente la justificación de estas dos perspectivas. Como sabemos, los dos elementos fundamentales de toda generación son para nuestro pensador: la misma edad y el contacto vital que, como afirma Ortega «juntos significan la comunidad de destino esencial» ${ }^{6}$. Aunque la edad no significa, para él, sólo una cierta y determinada fecha, sino siempre una zona de fechas, es necesario que los representantes de la misma generación sean coetáneos. Para Ortega es imprescindible distinguir los conceptos de «contemporaneidad»y «coetaneidad» porque, según sus palabras, «todos los que vivimos en el mismo hoy somos contemporáneos, pero sólo se coincide con los coetáneos» 7 .

Así podemos rechazar, muy fácilmente, la primera posición que coloca a Ortega en la generación del 98. El filósofo español no puede ser calificado como el representante de ese grupo porque no cumple el requisito fundamental de la misma edad. Miguel de Unamuno, Antonio Machado o Ramiro de Maeztu son contemporáneos de Ortega, viven en el mismo «hoy», pero no son sus coetáneos y forman la generación anterior a Ortega. Las afinidades entre la filosofía orteguiana y el programa intelectual de dicha generación parten de la idea de que: «las generaciones nacen unas de otras» ${ }^{8}$ y vivir significa para ellas «una faena de dos dimensiones, una de las cuales consiste en recibir lo vivido - ideas, valoraciones, instituciones, etc.- por la antecedente; la otra, dejar fluir su propia espontaneidad»?.

Ahora bien, como la primera interpretación deviene falsa, según el cálculo cuasi matemático del método de las generaciones de Ortega, no hay ninguna duda de que la segunda, que incorpora al filósofo español a la generación del 14, resulta acertada. Ortega fue el representante de dicha generación junto con Eugenio d'Ors, Manuel Azaña, Gregorio Marañón, Claudio Sánchez Albornoz, Américo Castro, Manuel García Morente, Ramón de Basterra, Corpus Barga y Pablo de Azcárate. Tal tesis confirma tanto el cumplimiento de los dos elementos fundamentales, indicados por Ortega, de toda generación: la misma edad y el contacto vital; como su integración en el programa intelectual de este grupo que se refleja, sobre todo, en sus ideas sociales y políticas comunes.

5 Véase las reflexiones sobre este tema en M. Menéndez Alzamora, La Generación del 14. Una aventura intelectual. Madrid: Siglo XXI, 2006, pp. 61-98 y 263-327.

6 J. Ortega y Gasset, En torno a Galileo, en Obras completas VI. Madrid: Revista de Occidente/Taurus, 2006, p. 394.

7 Ibid., p. 393.

8 J. Ortega y Gasset, El tema de nuestro tiempo, op. cit., p. 564.

9 Ibid. 
Sin embargo, cabe advertir que la filiación entre Ortega y la generación del 14 no explica, de forma suficiente, la doctrina filosófica de nuestro pensador. La generación del 14 ilustra, más bien, una perspectiva de interpretar el pensamiento orteguiano que destaca, sobre todo, su compromiso en cuestiones relacionadas con la vida cultural y política de la España de la primera mitad del siglo XX.

No obstante, existe, tal vez, otra perspectiva de examinar la filosofía orteguiana - una perspectiva que permite vincular a Ortega con un movimiento filosófico denominado «post-neokantismo» y, en la obra orteguiana, «el grupo de 1911». Una orientación que explica el pensamiento de Ortega desde el punto de vista filosófico sensu stricto.

\section{EL CONCEPTO DEL POST-NEOKANTISMO}

según la definición que propone Kurt Walter Zeidler - profesor de Filosofía de la Universidad de Viena - en su libro Kritische Dialektik und Transzendentalontologie Der Ausgang des Neukantianismus und die post-neukantianische Systematik ${ }^{10}$, y que desarrolla y profundiza profesor de Filosofía de la Universidad de Silesia de Polonia Andrzej J. Noras ${ }^{11}$, el concepto del post-neokantismo abarca los pensadores que brotan de la tradición neokantiana y la superan renovando la reflexión ontológica. Para Zeidler y para Noras a este grupo se puede incorporar los filósofos que realizan una reinterpretación de la filosofía de Kant - respecto a las doctrinas previas neokantianas limitadas a la teoría del conocimiento - centrándose en la ontología kantiana, olvidada por los maestros neokantianos ${ }^{12}$. Zeidler indica el año 1924, fecha del fallecimiento de Paul Natorp, uno de los profesores quien junto con Hermann Cohen formó la escuela neokantiana de Marburgo y de Alois Riehl, neokantiano realista,

10 Véase el libro de K. Walter Zeidler, Kritische Dialektik und Transzendentalontologie. Der Ausgang des Neukantianismus und die post-neukantianische Systematik R. Hönigswalds, W. Cramers, B. Bauchs, H. Wagners, R. Reiningers und E. Heintels. Bonn: Bouvier, 1995.

11 A. J. Noras, «Postneokantyzm wobec Kanta», Idea. Studia nad Struktura i Rozwojem Pojęć Filozoficznych, 16 (2004), pp. 79-88.

12 Véase la característica del movimiento neokantiano propuesta por Dussort, quien destaca la importancia de la recuperación de la lógica transcendental y del método kantiano en el neokantismo, sobre todo en el neokantismo marburgués, en el libro H. Dussort, L'École de Marbourg. Paris: PUF, 1963, p. 135. Véase también H. L. Ollig, Der Neukantianismus. Stuttgart: Metzler, 1979; E. W. Orth, Neokantianismus: Perspektiven und Probleme. Würzburg: Königshausen \& Neumann, 1994 y K. Ch. Köhnk, Entstehung und Aufstieg des Neukantianismus. Die deutsche Universitätsphilosophie zwischen Idealismus und Positivismus. Frankfurt am Main: Suhrkamp, 1986. Sobre las tendencias epistemológicas y positivistas del neokantismo, véase J. Ortega y Gasset, Filosofía pura. Anejo a mi folleto Kant, en Obras completas IV. Madrid: Revista de Occidente/Taurus, 2005, pp. 278-279. 
profesor de Filosofía de la Universidad de Berlín como la fecha central de dicho movimiento. Según la opinión de Zeidler esta fecha significa el fin del neokantismo y el nacimiento de una nueva filosofía llamada por él post-neokantismo, a la que incorpora filósofos como: Wolfgang Cramer, Hans Wagner, Robert Reininger y Erich Heintel ${ }^{13}$. Noras modifica la lista de Zeidler e indica como post-neokantianos a: Nicolai Hartmann, Heinz Heimsoeth, Karl Jaspers y Martin Heidegger ${ }^{14}$, es decir, la generación anterior respecto a los pensadores indicados por Zeidler.

Zeidler y Noras no citan a Ortega en sus libros, aunque si seguimos la perspectiva de los primeros podemos incluir al segundo en el grupo postneokantiano. Y ello por dos razones. Primero porque Ortega estudió, como Hartmann, Heimsoeth, Jaspers y Heidegger, en la escuela neokantiana - en su caso era la escuela de Marburgo - siendo uno de los mejores discípulos de Cohen y Natorp ${ }^{15}$. Por ello el pensamiento orteguiano brota directamente del neokantismo que influye de forma esencial en su formación filosófica ${ }^{16}$. En segundo lugar, la doctrina del raciovitalismo se puede caracterizar como una nueva ontología, basada, en la reinterpretación ontológica de la filosofía de Kant. Para demostrarlo podemos retomar dos ensayos de Ortega sobre el filósofo de Königsberg: Kant. Reflexiones del centenario (1724-1924) y Filosofía pura. Anejo a mi folleto Kant. El primero es del año 1924, fecha central del nacimiento de la filosofía post-neokantiana para Zeidler. En ambos trabajos se puede encontrar fragmentos que postulan la interpretación ontológica de la filosofía kantiana. Por ejemplo, en Kant. Reflexiones del centenario (1724-1924) Ortega estableció que «La nueva filosofía considera que la suspicacia radical no es un buen método. El suspicaz se engaña a sí mismo creyendo que puede eliminar su propia ingenuidad. Antes de conocer el ser no es posible conocer el conocimiento, porque éste implica ya una cierta idea de lo real. Kant, al huir de la ontología, cae, sin advertirlo, prisionero de ella. En definitiva, mejor

13 Dos filósofos del grupo que Zeidler denomina «post-neokantianos»: Cramer y Wagner según Hans Gustav Ollig deberían ser clasificados como «neo-neo-kantianos». Cf. H. G. Ollig, op. cit., pp. 94-110.

14 A. J. Noras, loc. cit., pp. 80-81.

15 Tal tesis confirman las cartas de Ortega escritas desde Marburgo en los años 19061907 a sus padres, amigos y a su novia Rosa Spottorno y Topete. Véase J. Ortega y Gasset, Las cartas del joven español (1891-1908). Madrid: El Arquero, 1991, pp. 47-676.

16 Sobre la indudable relación de Ortega con los maestros neokantianos: Cohen y Natorp escribe N. R. Orringer, Ortega y sus fuentes germánicas. Madrid: Gredos, 1979. Véase también el libro dedicado al problema de las huellas kantianas y neokantianas en Ortega de D. Leszczyna, José Ortega y Gasset. Dziedzictwo Kanta i neokantyzmu marburskiego. Breslavia: Arboretum, 2011. 
que la suspicacia es una confianza viva y alerta. Queramos o no, flotamos en ingenuidad, y el más ingenuo es el que cree haberla eludido» ${ }^{17}$.

Este postulado lo sostuvo Ortega también en su segundo ensayo sobre Kant Filosofía pura del año 1929, donde amplió su perspectiva ontológica afirmando que «Kant - sin darse tal vez cuenta perfecta de ello - ha modificado el sentido de la pregunta ontológica y, en consecuencia, la significación de la respuesta. Kant no quiere decir que las «cosas» del mundo se reducen a la «cosa» pensamiento, que los entes sean modos secundarios del ente primario pensamiento - lo que Kant rechaza y llama «idealismo material». Pero no se trata de los entes, sino de que el ser de los entes - cualesquiera que éstos sean, corporales o psíquicos, en tanto que cognoscibles - carece de sentido si no se ve en él algo que a las cosas sobreviene cuando un sujeto pensante entra en relación con ellas. Por lo visto, el sujeto pone en el universo el ser; sin sujeto no hay ser. Él, el sujeto por sí o en sí, tampoco tendría ser si él mismo no se lo pusiera al conocerse. De este modo se convierte el ser de «cosa» en acto. Pero no se recaiga en lo que precisamente queremos evitar: no se trata de que ahora lo único que es (donde $s e r=e n$ sí) resulte un acto, con lo cual no haríamos sino convertir al acto en una cuasi-cosa o quisicosa. No es el acto quien es, sino que el acto «produce» el ser, lo pone» ${ }^{18}$.

Ambos textos confirman la tesis de la ligazón de Ortega con post-neokantianos. Demuestran que el pensador español, como Hartmann, Heimsoeth, Jespers o Heidegger, consideraba la ontología como un elemento imprescindible para crear una nueva filosofía. Incluso fue un pionero en algunas cuestiones por delante de estos filósofos alemanes ${ }^{19}$.

17 J. Ortega y Gasset, Kant: Reflexiones del centenario (1724-1924), en Obras completas IV. Madrid: Revista de Occidente/Taurus, 2005, p. 261.

18 Ortega y Gasset, Filosofía pura, op. cit., p. 283.

19 Ortega ya en 1914 en su primer libro Meditaciones del Quijote estableció una nueva definición de verdad como «aletheia» por la que cabe entender una revelación o descubrimiento. Heidegger la introdujo casi quince años después publicando su famoso Sein und Zeit. Ortega fue también un pionero frente a Heidegger en sus pruebas de renovar la reflexión ontológica de Kant que aparecieron en 1924 en su ensayo Kant: Reflexiones del centenario (1724-1924) mientras que Heidegger realizó este proyecto en 1929 en Kant und das Problem der Metaphisik. Sobre el problema de la relación intelectual entre Ortega y Heidegger escribió, por ejemplo, A. Regalado García, El laberinto de la razón: Ortega y Heidegger. Murcia: Universidad de Murcia, 1990. Véase también el artículo de N. R. Orringer, «Ortega y Gasset's Dialogue with Heidegger in What is Philosophy?», en Ortega y Gasset Centennial/ University of New Mexico. Madrid: José Porrúa Turanzas, 1985, pp. 45-56. 


\section{LAS PROBLEMAS RELACIONADOS CON EL CONCEPTO DEL POSTNEOKANTISMO}

El concepto de post-neokantismo, aunque sigue siendo apropiado para interpretar la filosofía de la primera mitad del siglo XX, puede despertar algunas dudas, que podemos sintetizar en tres apartados.

En primer lugar, el concepto de post-neokantismo puede provocar un malentendido, porque el neokantismo no fue un movimiento uniforme, sino que abarcó múltiples variaciones. Algunos expertos afirman incluso siete direcciones en la filosofía neokantiana ${ }^{20}$. Otros distinguen entre el «primer neokantismo», que consiste en la actividad filosófica de Otto Liebmann, Friedrich Albert Lange, Kuno Fischer o Hermann Helmholtz, y «el neokantismo superior» $\mathrm{o}$ «el neokantismo exacto» que se refiere a las dos escuelas neokantianas: la escuela de Marburgo y la escuela de Baden. Sin embargo, también entre los representantes de la misma escuela neokantiana hay grandes diferencias. Por ejemplo, se suele decir que la filosofía de Cohen y de Natorp fue la misma filosofía ${ }^{21}$. Tal afirmación es falsa. Lo observamos en las obras tardías de Natorp que proceden de los años veinte en las que entra en las zonas intactas por Cohen aproximándolo más al idealismo postkantiano o a la filosofía de la vida que al neokantismo ${ }^{22}$. Por ello, utilizando el concepto post-neokantismo no se aclara a qué neokantismo nos referimos, provocando errores y malentendidos que tienen consecuencias muy graves en la historia de la filosofía.

20 Lo que cabe señalar respecto al movimiento neokantiano es su carácter amplio y complejo, que permite distinguir en él siete direcciones generales: primera: criticismo fisiológico representado por Hermann von Helmholtz, Friedrich Albert Lange y Hans Vaihinger; segunda: criticismo psicológico creado por Jocob Fries, Leonard Nelson y Hans Cornelius; tercera: criticismo metafísico en el que participaron Otto Liebmann y Friedrich Paulsen; cuarta: criticismo realista representado por Alois Riehl y Oswal Külpe; quinta: criticismo relativista, creado por Georg Simmel y Gustav Radruch; sexta: criticismo lógico de la escuela de Marburgo representado por Hermann Cohen, Paul Natorp y Ernst Cassirer y séptima, criticismo teórico-axiológico de la escuela de Baden en el que participaron Wilhelm Windelband, Heinrich Rickert y Emil Lask. Tal tipología del neokantismo aparece en la obra de F. Überweg, Grundriss der Geschichte der Philosophie. Die deutsche Philosophie des XIX. Jahrhunderts und der Gegenwart IV. Berlin: Mittler, 1923, p. 417. Véase también la clasificación del neokantismo que presenta J. Kiersnowska-Suchorzewska, «Metafizyka Kanta w świetle polemiki neokantystów», Przegląd Filozoficzny, 40 (1937), p. 367.

21 Tal tesis defendió Władysław Tatarkiewicz, filósofo polaco y discípulo de Cohen y Natorp, quien junto con Ortega estudió en 1911 en la Universidad de Philipps de Marburgo. En sus recuerdos Tatarkiewicz estableció que «Ambos profesores: Cohen y Natorp presentaron la misma actitud filosófica». Véase W. Tatarkiewicz, «Wspomnienia z Marburga», en P. Parszutowicz (eds.), Szkoła marburska i jej idealizm. Kęty: Wydawnictwo Marek Derewiecki, 2010, p. 26.

22 Véase las obras tardías de P. Natorp, Vorlesungen über praktische Philosophie. Erlangen: Philosophische Akademie, 1925 y Philosophische Systematik. Hamburg: Felix Meiner Verlag, 1958. 
En segundo lugar, el post-neokantismo entendido como renovación de la ontología es una perspectiva muy estrecha. En los post-neokantianos hay múltiples afinidades. Por ejemplo, un postulado de filosofar a la manera sistemática $^{23}$ o superar el idealismo de la filosofía moderna ${ }^{24}$.

En tercer lugar, el concepto de post-neokantismo, tiene, en mi opinión, demasiada dependencia de la filosofía neokantiana, mientras que la obra de Hartmann, Heimsoeth, Jaspers, Heidegger y Ortega se caracteriza por la originalidad de integrar el neokantismo con otras direcciones filosóficas como la fenomenología, el existencialismo o la filosofía de la vida. Sin embargo, el intento de encuadrarlos como neokantianos, fenomenólogos o existencialistas empobrece su pensamiento y deforma el sentido de su filosofía.

Todas estas razones nos permiten interpretar la filosofía de este grupo a partir del concepto orteguiano de generación y el concepto de la generación del 11 en particular. Para ello nos basamos en uno de los textos fundamentales de Ortega - Prólogo para alemanes - donde presenta los motivos esenciales de su filosofía, rememorando su estancia en las universidades alemanas de Leipzig, Berlín y Marburgo. Este ensayo es clave para interpretar su doctrina filosófica, presentando las relaciones que la unen con el programa intelectual de la generación llamada por él «el grupo del 11».

\section{Ortega y sus estudios en Alemania}

Ortega pasó casi cuatro años en Alemania ${ }^{25}$. Primero en la Universidad de Leipzig, famosa por sus bibliotecas, donde fue un discípulo de Wilhelm

23 En 1912 Hartmann publicó su artículo sobre el método sistemático que se convirtió en uno de los postulados fundamentales del grupo «post-neokantiano», del "grupo del 11". Véase N. Hartmann, «Systematische Methode», Logos, 3 (1912), pp. 121-163.

24 El proyecto de la superación del idealismo en el grupo post-neokantiano aparece por la primera vez en Hartmann en su artículo «Diesseits von Idealismus und Realismus. Ein Beitrag zur Scheidung des Geschichtlichen und Übergeschichtlichen in der Kantischen Philosophie», Kantstudien, 29 (1924), pp. 160-206. Véase también N. Hartmann, Die Seits Von Idealismus Und Realismus. Ein Beitrag Zur Scheidung Des Geschichtlichen und Übergeschtlichen in Der Kantischen Philosophie. Berlín: Heise, 1924. Sobre la superación del idealismo en Ortega, véase A. Rodríguez Huéscar, La innovación metafísica de Ortega: crítica y superación del idealismo. Madrid: Biblioteca Nueva, 2002 y N. R. Orringer, Nuevas fuentes germánicas de ¿Qué es filosofía? de Ortega. Madrid: Consejo Superior de Investigaciones Científicas, Instituto de Filosofía «Luis Vives», 1984, pp. 85-100.

25 Sobre los estudios de Ortega en Alemania, véase J. San Martín, «Ortega en Alemania», en J. Lasaga (eds.), El Madrid de Ortega. Madrid: Sociedad Estatal de Conmemoraciones Culturales, Publicaciones de la Residencia de Estudiantes, 2006, pp. 331-248. Véase también D. Leszczyna, José Ortegi y Gasseta studia na niemieckich uniwersytetach. Cracovia: Aureus, 2012. 
Wundt, el gran especialista en psicología, y de Maximilian Heinze, profesor de historia de la filosofía y de lógica. En Leipzig Ortega tuvo su primer encuentro con La crítica de la razón pura de Kant, tan complicada para él por su «cabeza latina» ${ }^{26}$. Además amplió su conocimiento sobre Kant leyendo y analizando las obras de los neokantianos. En este período sus lecturas, entre otras, fueron: Geschichte des Materialismus und Kritik seiner Bedeutung in der Gegenwart (de Friedrich Albert Lange) ${ }^{27}$, Philosophie der Griechen (de Eduard Zeller) ${ }^{28}$, Kants Theorie der Erfahrung (de Hermann Cohen ${ }^{29}$ o el Geschichte der Philosophie (de Karl Vorländer) ${ }^{30}$.

Sin embargo, la atmósfera cerrada y hermética de Leipzig no le satisfacía a Ortega, que se sentía muy sólo y perdido. Además no encontró allí lo que buscaba, es decir, un maestro en Filosofía, bajo cuya disciplina pudiera conquistar un nivel propiamente filosófico y un conocimiento profundo de la doctrina kantiana. Por ello, después de sólo un cuatrimestre decidió dejar Leipzig y trasladarse a Berlín, a donde llegó en noviembre de 1905. Comenzó sus estudios en esa Universidad recomendado por Carl Stumpf, director del Instituto Berlinés de Psicología y buen amigo de Miguel de Unamuno. Allí Ortega estableció las relaciones intelectuales con dos famosos kantianos: Georg Simmel, el precursor del criticismo relativista, y Aloiz Riehl, el representante del criticismo realista. Estos encuentros dejaron en él una profunda huella e influyeron en su decisión de continuar los estudios en la Universidad de Philipps en Marburgo ${ }^{31}$. La conexión entre Berlín y Marburgo fue para Ortega su maestro Simmel, quien en su seminario sobre Kant a menudo afirmaba que la más grande autoridad de la filosofía kantiana era el neokantista Cohen ${ }^{32}$.

26 J. Ortega y Gasset, Prólogo para alemanes, en Obras completas IX. Madrid: Revista de Occidente/Taurus, 2009, p. 135.

27 F. A. Lange, Geschichte des Materialismus und Kritik seiner Bedeutung in der Gegenwart. Leipzig: Iserlohn, 1887.

28 E. Zeller, Philosophie der Griechen. Tübingen: Fues, 1862.

29 H. Cohen, Kants Theorie der Erfahrung. Berlín: Dümmler's Verlagsbuchhandlung, 1871.

30 K. Vorländer, Geschichte der Philosophie. Leipzig: Durr, 1903.

31 Sobre la influencia de Simmel en la filosofía de Ortega escriben, por ejemplo, N. R. Orringer, Ortega y sus fuentes germánicas, op. cit., pp. 29-32, 293-315 y L. Rabi, «Georg Simmel, Ortega y Gasset y el retorno a la metafísica tradicional: rumbo a una filosofía de la vida», Revista de Estudios Orteguianos, 23 (2011), pp. 83-106. Véase también M. L. Perez Cavana, Der Konflikt zwischen dem Begriff des Individuums und der Geschlechtertheorie bei Georg Simmel und Ortega y Gasset. Freiburg: Centaurus-Verlagsgesellschaft, 1991.

32 Véase la biografía de Ortega escrita por J. Zamora Bonilla, Ortega y Gasset. Barcelona: Plaza y Janés, 2002, p. 59. 
Ortega, gracias a Simmel, tomó la decisión de ir a esta pequeña ciudad gótica, a donde llegó en octubre de $1906^{33}$.

En Marburgo Ortega encontró, por fin, sus verdaderos maestros filosóficos: el gran Cohen - «un gobernador de la ciudadela neokantiana» ${ }^{34}$ y Natorp. Allí también conoció a Hartmann, Heimsoeth, Scheffer o Tatarkiewicz, con quienes discutía sobre la filosofía de Parménides, Platón y Kant. A la vez que asistía a los cursos universitarios.

En este lugar hay que destacar que las clases de filosofía en Marburgo seguían la interpretación racionalista e idealista de los marbugueses, ateniéndose únicamente a las doctrinas de Parménides, Platón, Descartes, Leibniz y $\mathrm{Kant}^{35}$. Así, en la Universidad de Philipps no se leían ni las obras de los filósofos británicos, como Locke, Berkeley o Hume, ni las de los postkantianos alemanes. Imperaba un neokantismo basado en una relación estrecha entre filosofía y matemática.

Al principio Ortega aceptó el neokantismo ${ }^{36}$. Lo confirman sus textos y sus artículos periodísticos publicados entre los años 1907-1910. Por ejemplo: El método transcendental de Descartes ${ }^{37}$, Adán en el Paraíso ${ }^{38}$ o La pedagogía social como programa político ${ }^{39}$. Lo confirma también su famosa polémica con Ramiro de Maeztu, en la que Ortega postulaba la necesidad de dejar atrás lo individual y subjetivo y renovar el interés por lo objetivo e ideal. Además su fascinación por la filosofía idealista queda evidenciada en las cartas de Marburgo que Ortega escribía a sus padres y a su novia Rosa. En ellas les transmitía la idea fundamental en su «íntima cátedra» ${ }^{40}$ de que la realidad no es algo que se puede ver o tocar, sino que la crea el pensamiento o la conciencia.

33 Véase A. Galego Morell, «Ortega en Marburg», Cuadernos Hispanoamericanos: Revista Mensual de Cultura Hispánica, January - March (1984) pp. 403-405, 441-444.

34 J. Ortega y Gasset, Prólogo para alemanes, op. cit., p. 136.

35 Véase la característica de la filosofía marburguesa en W. Tatarkiewicz, loc. cit., p. 27.

36 Sobre la influencia de los marburgueses en el joven Ortega escribe M. S. Gardón, «Presencia de algunos temas neokantianos en el joven Ortega», Cuadernos Salamantinos de Filosofia, 6 (1979), pp. 359-377 y «La filosofía política del joven Ortega desde el neokantismo de Marburgo», Cuadernos Salamantinos de Filosofia, 8 (1981), pp.207-230.

37 J. Ortega y Gasset, El método transcendental de Descartes, en Obras completas I. Madrid: Revista de Occidente/Taurus, 2004, pp. 390-397.

38 J. Ortega y Gasset, Adán en el Paraiso, en Obras completas II. Madrid: Revista de Occidente/Taurus, 2004, pp. 58-76.

39 J. Ortega y Gasset, La pedagogía social como programa político, op. cit., pp. 86-102.

40 J. Ortega y Gasset, Diario de Marburgo, en Obras completas VII. Madrid: Revista de Occidente/Taurus, 2007, p. 95. 
Sin embargo, Ortega empezó a cambiar su posición intelectual frente a la filosofía idealista en general y a la doctrina neokantiana en particular en el año 1911, durante su segunda estancia en Marburgo. Ese cambio fue provocado por su primer «cuerpo a cuerpo» con la fenomenología. En la revista de la escuela neokantiana de Baden, Logos, apareció en 1911 una obra decisiva de Edmund Husserl, «Philosophie als strenge Wissenschaft», que causó un impacto en el grupo de los jóvenes estudiantes de Marburgo. En este año Ortega se incorporó al grupo formado por Hartmann para estudiar los clásicos en la filosofía como: Platón, Descartes y Kant, basándose en la fenomenología y en su postulado fundamental: «la vuelta a las cosas mismas» ${ }^{41}$.

En este período en Marburgo se gestó una nueva generación filosófica que, como afirma Ortega, «no era ya neokantiana» ${ }^{42}$. Según nuestro pensador la fecha decisiva para este grupo fue el año 1911, no sólo por los acontecimientos filosóficos ya mencionados, es decir por la erupción de la fenomenología, sino también por la importancia de esta fecha para la evolución intelectual de los jóvenes estudiantes de Marburgo: en 1911 andaban en torno a los veintiséis años - la edad decisiva según el método orteguiano de las generaciones. «Es un momento - estableció Ortega en Prólogo para alemanes - en que el hombre - me refiero por lo pronto al filósofo - comienza a no ser meramente receptivo en los grandes asuntos, sino que empieza actuar su espontaneidad. Búsquese en la biografía de los pensadores y se hallará que con sorprendente frecuencia es la fecha de su veintiséis años aquélla en que dentro de ellos hicieron su germinal presentación los motivos intelectuales que van a ser más tarde su obra original $\gg^{43}$.

Así en este período apareció en los jóvenes estudiantes de Marburgo una convicción que hay que abandonar el «continente idealista» y, volviendo a Kant y a su interpretación ontológica, establecer una nueva filosofía basada en el postulado principal «más allá del idealismo y realismo».

\section{LA GENERACIÓN DEL 11 Y SU CRÍTICA AL NEOKANTISMO}

los estudiantes de Marburgo: Hartmann (1882), Heimsoeth (1886) y Ortega (1883) tenían en torno a los veintiséis años en 1911, edad que según Ortega

41 Sobre las relaciones que unen a Ortega con el movimiento fenomenológico y que presentan la influencia de la fenomenología en la trayectoria filosófica orteguinana escribe J. San Martín, La fenomenología de Ortega y Gasset. Madrid: Biblioteca Nueva, 2012. En este libro el autor establece que la fenomenología es llave para entender a Ortega, destacando, a la vez, que tal afirmación no elimina otras posibles perspectivas de interpretar la filosofía orteguiana. Véase también P. W. Silver, Fenomenología y razón vital: genesis de „Meditaciones del Quijote” de Ortega y Gasset. Madrid: Alianza Editorial, 1978.

42 J. Ortega y Gasset, Prólogo para alemanes, op. cit., p. 150.

43 Ibid., p. 143. 
significa descubrir en sí «una cierta decisión o voluntad de que la verdad posea determinado sentido y consista en ciertas $\operatorname{cosas}\rangle^{44}$.

Esta decisión constituye la base intelectual de cada generación y contiene dos elementos fundamentales: primero, la negación de las ideas características de la generación anterior, entendiendo que la negación no significa un simple rechazo, sino una conservación y se transforma, en un «hueco de la nueva idea» o en una «anticipación del deseo»; segundo, un nuevo programa intelectual que constituye el fundamento para crear una nueva filosofía.

Respecto al primer elemento cabe advertir que la posición ante la filosofía neokantiana de los representantes de la generación del 11 fue bastante ambivalente. Por un lado, se consideraban deudores de sus maestros marburgueses que les enseñaron a hacer filosofía a la manera crítica y les permitieron conocer a fondo la doctrina kantiana pero, por otro lado, se dieron cuenta de los nuevos objetivos filosóficos que planteaba la nueva época histórica.

Por ello la crítica del neokantismo propuesta por los filósofos del grupo del 11 brota de una sensibilidad histórica muy amplia que les permite situar la filosofía neokantiana en una doble perspectiva filosófica: por una parte en la caída dramática del idealismo alemán y, por otra, en el nacimiento del positivismo y la filosofía de la vida.

Así, los neokantianos afrontaron una lucha con dos frentes: el positivismo que negaba la autonomía de la filosofía y las tendencias irracionalistas de la filosofía de la vida. Esta fue la razón por la que la generación de Cohen, Natorp, Windelband y Rickert volvió a Kant, cuya doctrina garantizaba la autonomía de filosofía y, a la vez, la vinculaba con la ciencia. Sobre esta tarea del neokantismo Ortega afirmó en su Prólogo para alemanes en las siguientes palabras: «La gleba europea quedó sembrada de sal para los efectos filosóficos. Con una velocidad increíble se olvidó la técnica del pensamiento que la filosofía usa. Fue una recaída en la infancia y el balbuceo intelectual. De aquí que las generaciones de 1840 y 1855 tuviesen que volver a la escuela, es decir a los clásicos. Fue preciso reaprender las primeras letras de la filosofía. Ya Trendelenburg - tres generaciones antes - se había agarrado a Aristóteles. Liebmann, Cohen, Windelband, Riehl fueron al aula de Kant. Éste es el gran sentido que tuvo el neokantismo: una necesidad escolar del europeo recaído en puerilidad filosófica» ${ }^{45}$.

Sin embargo, Ortega advierte que la devoción de los neokantianos hacia Kant fue tan intensa que los aprisionó, generando una interpretación muy hermética de su filosofía, limitada sólo a la teoría del conocimiento. «Kant - escribió Ortega en su ensayo Filosofía pura - fue descubierto hacia 1870. 
Aquella generación hizo un genial esfuerzo para reconstruir el pensamiento kantiano. Eran tiempos de positivismo, que quiere decir no-filosofía. Los neokantianos - Cohen, Riehl, Windelband - eran hombres de su tiempo, de alma positivista. Pero su sensibilidad filosófica les hizo presumir que el positivismo no era filosofía, sino ciencia particular aplicada a temas filosóficos. Por eso buscaron un maestro de filosofía bajo cuya disciplina cupiese reconquistar el nivel propiamente filosófico. Les faltaba ante Kant libertad; era ya faena sobrada conseguir reentenderle» ${ }^{46}$.

Para el grupo del 11 la filosofía neokantiana, con su postulado esencial «zurück zu Kant!»" ${ }^{47}$, presentaba una actitud vital inauténtica. No existe un zurück. Lo único que hay es un hombre que tiene que seguir al «imperativo de autenticidad», al «imperativo de invención», utilizando su facultad primordial que es la fantasía. El hombre es, pues, como afirma Ortega, «novelista de sí mismo» y su vida «es faena poética, invención del personaje que cada cual, que cada época tiene que ser $»^{48}$.

Así destaca Ortega que las generaciones neokantianas de 1840 y de 1855 vivieron con una filosofía que no era la suya, que era más bien «prestada». Pero a la vez afirma que esta inautenticidad del neokantismo no era una culpa, sino era un destino y que «lo mejor que aquellos hombre podían ser era neokantianos ${ }^{49}$. Gracias a su actividad intelectual se ha elevado el nivel de la filosofía que, como escribe Ortega «fue decisivo porque, más que todo en la vida, la filosofía es nivel» $»^{50}$.

Resumiendo, la crítica al neokantismo propuesta por los representantes del grupo del 11 abarca, según Ortega, cuatro elementos esenciales:

En primer lugar, los estudiantes de Cohen y Natorp destacan el carácter hermético de la filosofía de sus maestros que se limitaron sólo a las doctrinas que configuran las fuentes del idealismo transcendental de Kant. Así se concentraron en los estudios sobre Parménides, Platón, Descartes y Leibniz que realizaron bajo una perspectiva racionalista e idealista de inspiración kantiana. «Marburg - como anota Ortega - era el burgo del neokantismo. Se vivía dentro de la filosofía neokantiana como en una ciudadela sitiada, en perpetuo: ¡Quién vive! Todo en torno era sentido como enemigo mortal: los positivistas y los psicologistas, Fichte, Schelling, Hegel. Se les consideraba tan hostiles, que no se les leía. En Marburg se leía sólo a Kant y, previamente traducidos al kantismo,

46 J. Ortega y Gasset: Filosofía pura, op. cit., pp. 278-279.

47 En 1865 apareció la obra de Liebmann, Kant und die Epigonen, la obra decisiva que inauguró el nacimiento del movimiento neokantiano, llamando al final de cada capítulo con las mismas palabras: «also müß nach Kant zurückgegangen werden».

48 J. Ortega y Gasset, Prólogo para alemanes, op. cit., pp. 137.

49 Ibid., p. 138.

50 Ibid., p. 136. 
a Platón, a Descartes, a Leibniz. Ciertamente que estos cuatro nombres son egregios, pero no es posible reducir todos los jugos de la historia universal a menor número de gotası 51 .

En segundo lugar, los representantes de la generación del 11 consideraban que los maestros neokantianos no enseñaban filosofía. Como dice Ortega: «Era preciso saberla ya de antemano, traerla aprendida desde el vientre de la madre $»^{52}$. Por ello nuestro pensador los comparó con los drusos del Líbano «que no son prosélitas porque, según ellos, para ser druso hay que haberlo sido desde toda la eternidad $»^{53}$.

Además los jóvenes que querían estudiar en Marburgo tenían que aceptar la perspectiva de Cohen y Natorp para obtener un conocimiento profundo de la filosofía kantiana. Era la perspectiva de interpretar al filósofo de Königsberg a la manera idealista, centrándose en su lógica transcendental ${ }^{54}$. «El grupo de jóvenes - escribió Ortega en su Prólogo para alemanes - que entre 19071911 aprendió en la ciudadela del neokantismo los usos de la milicia filosófica [...] no era ya neokantiano. No habíamos, sin embargo, perdido el tiempo por completo. Habíamos estudiado Kant a fondo y esto no es un grano de anís. Es más frecuente de lo que se cree que incluso filósofos de cierto rango arrastren toda su vida, como una cadena al pie, un insuficiente conocimiento de Kant. Este defecto no puede ser compensado porque en Kant hace el pensamiento europeo un giro de ciento ochenta grados y se constituye frente a todo el pasado en audaz paradoja» ${ }^{55}$

En tercer lugar, para la generación del 11 los maestros marburgueses, debido a «la voluntad de sistema» que caracterizaba la filosofía neokantiana, no despertaban la atención de los jóvenes estudiantes hacia nuevos problemas no contemplados en su programa intelectual. La voluntad de sistema de los marburgueses significa, para Ortega, que no les interesaban los problemas filosóficos ni la verdad sino que solo deseaban crear una construcción intelectual cerrada, es decir, un sistema. Como afirma Ortega: «(...) Los neokantianos no despertaban las mentes jóvenes hacia problemas abiertos (...) No se conocían más cuestiones que las resueltas ya en su canon. En general, todas las escue-

51 Ibid.

52 Ibid.

53 Ibid.

54 Este rasgo del neokantismo marburgués destacó Hartmann, quien clasificó la filosofía de la escuela de Marburgo como «idealismo lógico». Este tipo del idealismo se caracteriza por un subjetivismo lógico, donde el sujeto y objeto se dispersan en la esfera lógica. N. Hartmann, Grundzüge einer Metaphysik der Erkenntnis. Berlín: Walter de Gruyter, 1965, pp. 160-167.

55 J. Ortega y Gasset, Prólogo para alemanes, op. cit., p. 141. 
las neokantianas se han caracterizado por su escaso repertorio de problemas, inquietudes y curiosidades $\rangle^{56}$.

En cuarto lugar, la voluntad de sistema de los neokantianos «forzó» su manera de hacer filosofía. Según Ortega aunque los estudiantes de Marburgo consideraban las filosofías neokantianas como «profundas, serias, agudas, llenas de verdades ${ }^{57}$, advirtieron, a la vez, que les faltaba cierta veracidad.

Según Ortega por veracidad cabe entender «el afán de verdad, el ansia de llegar a estar en lo cierto» ${ }^{58}$. Y la falta de esta virtud llevó a los marburgueses al estilo «ortopédico» de pensar y hacer la filosofía, es decir, a interpretar los clásicos filosóficos como Platón, Descartes, Leibniz traduciéndoles al kantismo. Ortega describió esta tendencia neokantiana en su Prólogo para alemanes con las siguientes palabras: «Había mucho de ortopedia en aquel estilo de pensar. Se tomaba un autor o una ciencia - Descartes o la matemática o la jurisprudencia - y se le obligaba a decir, velis nolis, lo que previamente se había resuelto que dijesen. El caso de Natorp con respecto a Platón es ejemplar e increíble. Este Natorp, que era un hombre buenísimo, sencillo, tierno, con un alma de tórtola y una melena de Robinson Crusoe, cometió la crueldad de tener doce o catorce años a Platón encerrado en una mazmorra, tratándolo a pan y agua, sometiéndolo a los mayores tormentos para obligarle a declarar que él, Platón, había dicho exactamente lo mismo que Natorp $»^{59}$.

Para la generación del 11 esta falta de veracidad en los neokantianos les aproximaba al idealismo de Fichte, Schelling y Hegel, enemigos mayores de Cohen y Natorp. Sin embargo esta tendencia de los neokantianos y postkantianos se revela en su misma fuerza constructiva y en la falta de pulcritud en su terminología, que provoco, como dice Ortega que: «Aquellos hombres no partían humildemente en busca de las asnillas de Saúl, sino que marchaban decididos a conquistar el reino de un sistema, fuera como fuera» ${ }^{60}$.

VII. El PROGRAMA INTELECTUAL DE LA GENERACiÓN DEL 11

Ahora bien, la crítica de la filosofía neokantiana se transforma por la generación del 11 en un programa intelectual positivo y nuevo que abarca cuatro elementos según Ortega:

Primero, renovar la noción de veracidad. Por ello el grupo del 11 indagó en el ámbito de la fenomenología con su postulado «la vuelta a las cosas mismas», que garantizaba la sinceridad filosófica. Esta última cosa significa, para nuestro 
pensador, presentar las cosas como verdaderamente «son», sin interpretaciones forzadas. Al ejemplo de Hartmann, amigo de Marburgo, de quien Ortega afirma: «con tan extrema pulcritud se detiene donde la cosa empieza a no estar clara y se vuelve al lector diciéndole: "Sobre esto no sé más"»61. Según Ortega el deseo de averiguar la verdad es una necesidad constitutiva del hombre. No se puede vivir sin verdad, no se puede vivir de mitos, porque la vida sin verdad no es vivible. El hombre necesita la verdad como necesita el aire para respirar. Por ello nuestro pensador dice que «Zoológicamente habría, pues, que clasificar al hombre, más que como carnívoro, como Wahrheitsfresser (verdávoro)» ${ }^{62}$.

Segundo, hacer filosofía a la manera sistemática, es decir, empezando por los problemas filosóficos y no por las construcciones mentales o sistemas, sin que esto signifique una renuncia a la voluntad de sistema. El sistema es la «honradez» del pensador, es su obligación y requiere que su filosofía, su pensamiento, sea cosmos, universo. Pero el sistema no puede ser, como en los postkantianos o en marburgueses, el punto de partida de la reflexión filosófica, sino más bien su resultado. Por ello afirma Ortega que el sistema no puede ser una obra juvenil. Hay que dejar «el fruto maduro para la hora madura, la cual, según Aristóteles afirma con un azorante exceso de precisión, son los cincuenta y un año» ${ }^{63}$.

Tercero, recuperar la reflexión ontológica, frente al neokantismo que reduce toda la filosofía a la teoría del conocimiento repitiendo la vieja fórmula idealista que «el ser es pensar» ${ }^{64}$.

Mas para la generación del 11 existe otra manera de abordar la pregunta fundamental de la ontología «¿qué es el ser?». Y consiste en advertir que tal pregunta no significa sólo «quién es el ser» sino también «qué es el ser mismo como predicado», es decir, el ser no significa ser en sí, sino «la relación a un sujeto teorizante». Sin embargo esta relación no nos lleva a la interpretación idealista de los postkantianos y neokantianos porque, el ser abarca siempre

61 Ibid., p. 149.

62 Ibid., p. 148.

63 Ibid., p. 149.

64 La reflexión ontológica aparece en todos filósofos de la generación post-neokantiana. En Heidegger encontramos el proyecto de la ontología fundamental, en Hartmann la ontología crítica, en Jaspers la ontología entendida como Periechontologie y en Ortega aparece la ontología de la vida de cada cual. Véase los trabajos de J. Stallmach, Ansichsein und Seinverstehen: Neue Wege der Ontologie bei Nicolai Hartmann und Martin Heidegger. Bonn: Bouvier, 1987; A. Rinofner, «Periechontologie und Weltgeschichte der Philosophie. Sistematische Bemerkungen zu einem aufschluss reichen Verhältnis», en L. H. Ehrlich y R. Wisser (eds.), Karl Jaspers. Philosophy on the Way to World Philosophy.Würzburg-Amsterdam: Königshausen \& Neumann \& Rodopi, pp. 51-60 y A. Cobián y Macchiavello, La ontología de Ortega y Gasset. Lima: Publicaciones del Instituto Riva-Aguero, 1960. 
tanto el sujeto como las cosas, es una relación que, como dice Ortega, «no traía consigo la absorción de las cosas en el pensamiento ni en el sujeto» ${ }^{65}$.

Cuarto, superar el idealismo, es decir, abandonar el concepto de la «conciencia» que es un tumor que devora el mundo real, lo encierra dentro de su «prisión» y convierte lo real en su propio contenido ${ }^{66}$.

Sin embargo, este último elemento, es decir, la superación del idealismo no significa para los representantes de la generación del 11 una negación, sino su conservación. Es necesario conservar la tesis idealista fundamental: «la existencia de las cosas depende del sujeto» pero, al mismo tiempo, hay que reconocer su sentido. Según la interpretación idealista esa «dependencia» significa que las cosas, el mundo y toda exterioridad forman el contenido de la conciencia o son productos del yo. Los idealistas, tanto postkantianos como neokantianos, comprenden la relación entre sujeto y objeto de manera unilateral, no recíproca, convirtiendo la realidad en un espectáculo, una apariencia, o un mero sentido.

Por el contrario, para la generación del 11, lo que existe verdaderamente, lo que es dado, positivo, puesto por sí y no construido o manipulado por la mente, es la realidad de la vida donde el sujeto se encuentra con las cosas mismas, con el mundo. El error del idealismo fue convertirse en el subjetivismo, que significa destacar la dependencia de las cosas del pensamiento que las produce. Por ello, en el idealismo el sujeto se traga el mundo exterior y es como establece Ortega «un tumor que es preciso operar» ${ }^{67}$.

No obstante, aunque cada generación se caracteriza por una determinada sensibilidad vital convertida en un común programa intelectual o filosófico, no significa que todos sus miembros se integren en dicho programa de la misma manera. Los representantes de la generación del 11 también, aunque unidos por la misma misión histórica, realizan su programa intelectual a la manera diferente y autónoma. «Los veintiséis años - afirmó Ortega - (...) es el momento de más esencial partida para el individuo. Hasta entonces vive en grupo y del grupo. La adolescencia es cohesiva. El hombre, durante ella, ni puede ni sabe estar solo. Le domina lo que he llamado "instinto de coetaneidad" (...). Pero en esa jornada del curso vital del individuo parte hacia su exclusivo destino, que es, en su raíz, solitario. Cada cual va a cumplir a su modo la misión histórica de su generación. Porque cada generación no es, a la postre, sino eso: una determinada misión, ciertas precisas cosas que hay que hacer» ${ }^{68}$. Así cada hombre, cada filósofo vive en una determinada circunstancia, que forma su

65 J. Ortega y Gasset, Filosofia pura, op. cit., p. 284.

66 Sobre el proyecto de superar el idealismo en la filosofía post-neokantiana, véase N. R. Orringer, Nuevas fuentes germánicas de ¿Qué es filosofía?de Ortega, op. cit., pp. 85-100.

67 J. Ortega y Gasset, ¿Qué es filosofia?, en Obras completas VIII. Madrid: Revista de Occidente/Taurus, 2008, p. 331.

68 J. Ortega y Gasset, Prólogo para alemanes, op. cit., p. 150. 
única e indispensable perspectiva en la que ve las cosas. La vida es nuestra vida que no podemos transferir a otros. Nadie la puede vivir por nosotros. Por ello cada hombre cumple a su modo los objetivos que plantea ante él su época histórica, porque el destino humano es siempre intransferible y solitario.

Dorota Leszczyna, es Profesora adjunta de Filosofía Moderna en la Facultad de las Ciencias Sociales de la Universidad de Breslavia (Wrocław) de Polonia y Doctora en Filosofía por la misma universidad polaca. Es autora de dos libros sobre Ortega y sus relaciones con la filosofía alemana: El legado de Kant y del neokantismo marburques en José Ortega y Gasset, Breslavia: Arboretum, 2011, pp. 244 y José Ortega y Gasset y su formación en las universidades alemanas, Cracovia: Aureus, 2012, pp. 186 (ambos libros en polaco). Es traductora de diferentes textos españoles al polaco, entre los que se destacan tres ensayos de Ortega: Kant: reflexiones del centenario (1724-1924), Cracovia: Aureus, 2012, Filosofía pura. Anejo a mi folleto Kant, Cracovia: Aureus 2012 y Prólogo para alemanes, Cracovia: Aureus 2013. Es autora de más que 30 artículos sobre la filosofía española y alemana. También es miembro de la Sociedad Kantiana en Polonia

\author{
Dirección postal: \\ Dr Dorota Leszczyna \\ Instytut Filozofii \\ Wydział Nauk Społecznych \\ Uniwersytet Wrocławski \\ Ul. Koszarowa 3/20 \\ 51-149 Wrocław \\ Polonia
}

Correo electrónico: d.leszczyna@wp.pl 
